\title{
COVID-19 Olgularında Kardiyopulmoner Rehabilitasyon
}

\author{
Selda SARIKAYA (1) $\square$ \\ Zonguldak Bülent Ecevit Üniversitesi, Tip Fakültesi, Fiziksel Tip ve Rehabilitasyon Anabilim Dalı, Zonguldak, Türkiye \\ Bu makaleye yapılacak atıf: Sarıkaya S. COVID-19 Olgularında Kardiyopulmoner Rehabilitasyon. Türk Diyab Obez 2020;2: 177-182.
}

ÖZ

COVID-19 pandemisi toplumlarda benzeri görülmemiş bir sorun oluşturmuştur. Hastalarda ortaya çıan immobilizasyon, pulmoner, nöromüsküler ve bilişsel komplikasyonlar göz önünde bulundurulduğunda, rehabilitasyon uzmanları COVID-19 olan hastaların iyileşme sürecinde önemli bir rol oynayabilir. Birçok kronik hastalıkta kardiyopulmoner rehabilitasyonun (KPR) yararlı etkileri uzun zamandır bilinmektedir. COVID-19'da KPR’nin etkinliği ile ilgili bilimsel kanıtlar da artmaktadır. Bu çalışmalar ışığında, KPR programlarının COVID-19 hastalarında faydalı olacağı öngörülmektedir.

Anahtar Sözcükler: COVID-19, Pulmoner rehabilitasyon, Kardiyak rehabilitasyon

\section{Cardiopulmonary Rehabilitation in COVID-19 Patients}

\begin{abstract}
The global outbreaks of COVID-19 has created an unprecedented challenge to the society. Considering the immobilization, neurological, pulmonary, neuromuscular and cognitive complications, rehabilitation professionals can play an important role in the recovery process for patients with COVID-19. The beneficial effects of cardiopulmonary rehabilitation (CPR) in many chronic diseases have been known for a long time. Scientific evidence concerning the effectiveness of CPR in COVID-19 is also increasing. In the light of this studies, it is predicted that CPR programs will be beneficial in COVID-19 patients.
\end{abstract}

Key Words: COVID-19, Pulmonary rehabilitation, Cardiac rehabilitation

\section{GíRIȘ}

Coronavirüs hastalığı 2019 (COVID-19), tüm dünyayı kısa süre içerisinde etkisi altına alarak pek çok insanın ölümüne neden olmuştur $(1,2) .15$ Haziran 2020 tarihinde Türkiye'de toplam vaka sayısı 179831 ve ölüm sayısı 4825 olarak bildirilmiştir (3).

Dünya Sağlık Örgütü (DSÖ) yaptığı klinik sınıflamada COVID-19 hastalığını hafif semptomlu hastalık, pnömoni, şiddetli pnömoni, akut solunum zorluğu sendromu (ARDS), sepsis ve septik şok ile seyreden ileri dönem olmak üzere dört aşamaya ayırmaktadır $(3,4)$. COVID-19 hastalığının seyrinde olguların çoğunda hafif veya komplikas- yonsuz klinik tablo görülürken, hastaneye yatış gerektiren olguların bir bölümünde ise yoğun bakım ünitesinde tedavi gerekmektedir. Ağır olgularda, süreç içerisinde kanama bozuklukları, akut kalp hasarı, böbrek yetmezliği, sepsis ve septik şoku da içeren multiorgan yetmezliği görülmektedir (5). COVID-19 hastalarında en sık görülen komorbiditeler hipertansiyon (\%55), koroner arter hastalığ 1 ve inme (\%32) ve Diyabetes Mellitus (DM) (\%31) olarak bildirilmiştir(6). Ko-morbiditesi olan ve yaşlı bireylerde hastalık daha ağır seyretmektedir ve ölümlerin büyük bölümü bu gruplarda olmaktadır. Örneğin; KOAH varlığının ağır COVID-19 için 5 kattan fazla risk oluşturduğu bildirilmiştir (7). 
COVID-19 hastalarında görülen kardiyovasküler komplikasyonlardan bazıları aritmiler, akut kardiyak hasar ve şok tablosudur. Özellikle akut miyokardiyal hasarın prognostik öneme sahip olduğu belirtilmiştir (8). ARDS ve akut kardiyak hasarın birbirlerinden bağımsız olarak mortalite ile ilişkisi bildirilmiştir (8).

$\mathrm{Bu}$ derlemede ağırlıklı olarak COVID-19 hastalarında pulmoner tutulum ve pulmoner rehabilitasyondan bahsedilecektir.

\section{Pulmoner rehabilitasyon (PR)}

Pulmoner rehabilitasyon, akciğer hastalıkları, immobilite, cerrahi girișim gibi durumlarda medikal tedavilere ek olarak, etkili ve güvenli bir şekilde uygulanan bir tedavi yöntemidir (9).

Multidisipliner yaklaşım ile pulmoner rehabilitasyon kapsamında hastalara beslenme, psikososyal destek, günlük yaşam aktivitelerinin düzenlenmesi ve egzersiz eğitimi uygulanmaktadır.

Pulmoner rehabilitasyonda egzersiz eğitimin içinde birkaç başlık yer alır: Solunum kasları egzersizleri, aerobik egzersizler ve güçlendirme egzersizleri

Solunum kasları egzersizleri: Solunum kaslarının gücünü artıran egzersizlerdir. Dispneyi azaltırken, egzersiz kapasitesini ve yaşam kalitesini iyileştirir. Pulmoner hastalıkların tümünde nefes alıp-verme düzensiz ve yüzeyeldir. İnspirasyonla alınan havanın alveollere yeterince ulaşamaması yanında alveoldeki O2 düzeyi azalmış havanın hava yolları ile dışarı çıkarılamaması kişilerin hipoksi düzeyinin ve dolayısıyla dispnenin artmasına yol açar. Doğru solunum tekniklerinin kullanılması ile dispne ve solunum işi için harcanan enerji azalır. Bu amaçla kullanılan birçok egzersiz bulunmaktadır: büzük dudak solunumu, segmental solunum, diyafragmatik solunum, kurbağa solunumu ve gevşeme egzersizleri.

Bronşiyal hijyen teknikleri: Akciğer hastalıklarındaki temel sorunlardan biri mukus birikimidir. Bu nedenle pulmoner rehabilitasyonun basamaklarından birisi de mukusun atılmasını kolaylaştıracak yöntemlerin hastaya öğretilmesi ve gerekli durumlarda düzenli olarak uygulanmasıdır. $\mathrm{Bu}$ teknikler manuel veya bazı cihazların yardımı ile uygulanabilir

Aerobik ve kuvvetlendirme egzersizleri: Hem kardiyak rehabilitasyon (KR) hem de PR programları temel olarak aerobik / dayanıklılık/ endurans egzersizleri (bisiklet ergometresi, koşu bandı, kuzey yürüme eğitimi, serbest yürüyüş vb.) ve kuvvetlendirme / direnç egzersizlerini veya bu iki egzersiz yönteminin kombinasyonunu içerir. Kronik akciğer hastalıklarında hastaların günlük yaşamlarında zorlanmalarının önemli nedenlerinden biri kas güçsüzlügüdür. Omuz kuşağı ve sırt kasları aynı zamanda solunuma yardımcı kaslardır ve kronik akciğer hastalığı olan bireylerde temel solunum kaslarının yeterli çalışmaması nedeniyle gereğinden fazla çalışırlar ve yorulurlar.

COVID-19'a bağlı kardiyopulmoner komplikasyonların tedavisinde; fonksiyon kaybını, anksiyete ve depresyonu azaltmak, hastanın fiziksel işlevini korumak ve en üst seviyeye çıkarmak; sonuç olarak yaşam kalitesini artırmak için kardiyopulmoner rehabilitasyon (KPR) uygulamalarının önemli olacağ 1 öngörülmektedir (10). Ancak hastalıkla ilgili bilgilerin her geçen gün arttığ 1 bu dönemde halen, KPR'un uygulanma zamanı ve uygulanma niteliği konusunda kanıt gücü yüksek yeterli veri yoktur (9-11).

\section{COVID-19 Akut Döneminde Kardiyopulmoner} Rehabilitasyon

COVID-19 geçiren hastaların uzun dönemde pulmoner rehabilitasyon gereksinimleri olup olmayacağı bilinmemektedir. Akut dönem pulmoner rehabilitasyonu ile ilgili bazı klinik deneyimler ve öneriler bulunmaktadır (10, 12-18). "Türkiye Fiziksel Tip ve Rehabilitasyon Uzman Hekimleri Derneği Kardiyopulmoner Rehabilitasyon Çalıșma Grubu” tarafından "COVID-19 Pulmoner Rehabilitasyon Rehberi V 1.0" hazırlanmıştır. Bu rehberin temel önerileri Tablo 1'de verilmiştir $(9,18)$. COVID-19'un yüksek bulaş riski nedeni ile, her sağlık merkezi kendi sağlık personeli ve olanaklarını dikkate alarak rehabilitasyon programları planlamalıdır (3, $4,9)$.

Yoğun bakım hastalarında, eklem hareketlerinin devamlılığının sağlanması ve bası yarası gibi immobilizasyon komplikasyonlarının önlenmesi en önemli hedeflerdir (19). COVID-19'lu hastalarda korunma ve bulaşı azaltma ve kaynakların etkili kullanımı açısından bu egzersizler ve pozisyonlama uygulamaları hastanın yoğun bakım hemşiresi tarafindan da yapılabilir.

Hastaların genel durumunda iyileşme sağlandığında, ilk önce yatak-içi ve yatak kenarında oturma, daha sonra da ayakta durma ve yürüme aktivitelerine geçilmelidir. Hastaların dik pozisyon elde etmesi oksijenizasyonu artırması açısından son derece önemlidir (20). Ancak hastaların değişken stabiliteleri nedeniyle YBÜ ekibi ile birlikte hareket edilmelidir (21). Hasta yardım almaksızın 10 saniye boyunca ayakta durabildiğinde veya 3 kez yataktan kalkabildiği zaman, transfer egzersizlerine başlanabilir (19). Uzun süreli mekanik ventilasyonda kalan hastalarda aerobik eğitim ve kas güçlendirme egzersizlerinin, tek başına mobilizasyondan daha fazla yürüme mesafesinde artış sağladığı bildirilmiştir. Her türlü pulmoner rehabilitasyon uygula- 
ması sırasında hastanın stabilitesi bozulduğunda tedaviye son verilmelidir $(9,11)$.

COVID-19'un kardiyopulmoner sisteme direkt etkileri yanında hastalarda immobilizasyon, izolasyon ve karantina gibi uygulamalar sırasında fiziksel aktivitenin ileri düzeyde kısıtlanması bu bireylerin fizik kapasitelerinin belirgin olarak azalmasına neden olmaktadır. Ülkemizde hastalar, hastaneye yatışın gerekmediği durumlarda evde, yatış gerektiği durumlarda ise hastane odalarında tek kişi izole olacak şekilde bu süreci geçirmektedir. Sadece bir haftalık yatak istirahati bile kișide \%20'ye kadar ciddi kas kaybına neden olabilir(22). Bu nedenle genel durumu iyi olup izolasyon/karantina uygulanan hastaların bu dönemde hareketsiz kalmaması önemlidir. İzolasyonun gerekli olduğu bu hastalarda, sağlık profesyonellerinin korunması da ilk hedef olduğu için egzersiz programları, uygun olgularda, görsel materyalle desteklenmelidir. Bu amaçla Türkiye FTR Derneği COVID-19 çalışma grubu tarafından bir egzersiz formu oluşturulmuştur (23). Bu dönemde eklem hareket açıklığı, germe ve hastanın durumuna göre kas kuvveti ve dayanıklılığını artırmak amacıyla güçlendirme egzersizleri tedavi planında yer alabilir. Üst ekstremite için ağırlıklar veya elastik bantlar, alt ekstremite için kum torbaları ve elastik bantlar ile yapılacak egzersizler idealdir.

Alger ve ark. tarafından İtalya'da yürütülen bir çalışmada, COVID-19 akut dönemi sonrası hastalar PR için bir rehabilitasyon merkezinde tedaviye alınmıștır. Bu hastalarda O2 desteğinin azaltılması, fizik kondüsyonun artırılması amacıyla PR uygulamaları yapılmıştır. 1 ay süreyle tedavi alan hastaların \%45.9'u taburcu olabilmiş, \% 6.5'i ölmüş, kalan hastalarda yatmaya devam etmişlerdir. Hastaların büyük oranda $\mathrm{O} 2$ ihtiyacı azalmış ve mobilitelerinde artış

Tablo 1: COVID-19 Hastalık Dönemlerine Göre Pulmoner Rehabilitasyon Önerileri (TFTR Uzman Hekimleri Derneği, TFTR Derneği, Kardiyopulmoner Rehabilitasyon Çalışma Grubu (18).

\begin{tabular}{|c|c|c|}
\hline Hastalık Dönemi & $\begin{array}{c}\text { Pulmoner } \\
\text { Rehabilitasyon N (PR) }\end{array}$ & Ek Koşul ve Yöntem \\
\hline $\begin{array}{l}\text { Asemptomatik/ } \\
\text { Hafif Hastalık } \\
\text { Dönemi }\end{array}$ & PR endikasyonu yoktur. & $\begin{array}{l}\text { a. Özel durumda (immobilite, nörolojik, kronik } \\
\text { akciğer-kalp hastalı̆̆ vb.) bireysel yaklaşım } \\
\text { b. Genel sağlık önerileri } \\
\text { - Diyet } \\
\text { - Ev egzersiz programı }\end{array}$ \\
\hline
\end{tabular}

$\begin{array}{ll} & \begin{array}{l}\text { a. Genel durumu iyi, ateşi, dispnesi ve } \\ \text { takipnesi bulunmayan, oksijen saturasyonu }\end{array} \\ \text { Hafif Pnömoni } & \begin{array}{l}\text { normal hastada ve virüs yükü azaldiktan } \\ \text { Dönemi }\end{array} \\ & \begin{array}{l}\text { sonra, özel durumu olan hastaya FTR } \\ \text { uzman hekiminin konsültasyonu ile PR. }\end{array} \\ & \text { b. Kuru öksürükte PR endike değil. }\end{array}$

İlgili hekim tarafından Covid-19 pnömonisi tanısının konması ve ilaç tedavisinin başlanması sonrasında, genel durumunun stabil hale gelmesi (ateşinin düşmesi,

Ciddi Pnömoni Dönemi dispnenin azalmasi, solunum sayısının $<30$ solunum/dakika olmas1, $\mathrm{SpO} 2>\% 93$ olmas1 gibi) ve virüs yükünün azalması sonrasında (ortalama on gün sonra),

FTR uzman hekiminin uygun gördüğü hastaya PR.

a. Özel durumda (immobilite, nörolojik, kronik akciğer-kalp hastalığ $\mathrm{vb}$.) bireysel yaklaşım

b. Genel sağlık önerileri

- Diyet

- Ev egzersiz programı

c. KKE

d. Uygulamaların tek seans olarak hastaya gösterilmesi, ev programı verilmesi

a. Tibbi stabilite gerekli koşul.

b. PR sırasında bulgular kötüleşirse dur.

c. Özel durumda (immobilite, nörolojik, kronik akciğer-kalp hastalığı vb.) bireysel yaklaşım

d. KKE

e. Uygulamaların tek seans olarak hastaya gösterilmesi.

f. Hastanın uygulamaya devam etmesi ve gerekirse takip

a. Genel rehabilitasyon prensipleri bakım veren personel tarafından verilmeli.

ARDS PR endikasyonu yok. b. KKE

c. Genel durum düzeldikten sonra PR. 
elde edilmiştir (24). Araştırmacılar pandeminin kendine özgü tedavi algoritmaları geliştirilmesine yol açtığını belirtmişlerdir. COVID-19 hastalarında akut dönemde hayatta kalmayı sağlamak hedeflenirken, sağ-kalan bireylerin yaşamlarına devam edebilmeleri için rehabilitasyona ihtiyaç duydukları dile getirilmiştir $(6,10,12,25)$.

COVID-19 Kronik Döneminde Kardiyopulmoner Rehabilitasyon

ARDS, interstisiyel akciğer hastalığının (İAH) nedenlerinden biridir. COVID-19 seyrinde de İAH'de olduğu gibi hem pulmoner hem de ekstrapulmoner etkilenme olmaktadır. İAH'da pulmoner fibrozisin sitokin düzeylerinin artışı ve büyüme faktörlerinin ekspresyonuna neden olarak sistemik inflamasyonu tetiklediği saptanmıştır. Eşlik eden hiperkoagülopati ile birlikte inflamasyon aterotrombotik olaylara neden olabilmektedir. COVID-19 olgularında da benzer şekilde sitokin firtınası, beklenmedik trombotik olaylar görülebilmektedir. Bu nedenle elimizdeki verilere bakarak COVID-19'un pulmoner fibrozis kliniğine benzer bir seyir izleyeceğini söyleyebiliriz. Ancak ARDS'de olduğu gibi zamanla hastalarda pulmoner fonksiyonlarda iyileşmenin gözlenmesi mümkündür. ARDS hastalarında olduğu gibi COVID-19 hastalarında da kronik dönemde DLCO'da düşüklük devam edebilir (26).

ARDS hastalarının uzun dönemde takibinin yapıldığı Toronto ARDS takip çalışmasında, hastaların 5. yılda ortalama 6DYT mesafesi $436 \mathrm{~m}$ (normal mesafenin \% 76's1) bulunmuştur. Gençlerde yaşlı bireylere göre daha fazla iyileşme görülmüş, fakat her iki grup da 5 yıl sonunda öngörülen normal fiziksel fonksiyonlarına geri dönememiştir (27). Pulmoner diffüzyon kapasitesi, tüm çalışmalarda en çok etkilenen tek fonksiyonel değișkendir (27-29). Bu nedenle COVID-19 hastalarının takibinde de SFT yanında DLCO değerlendirmesinin de yapılması gerekli olabilir.

COVID-19'un akut döneminde orta ve ağır şiddette pnömonisi olan olgularda PR uygulamaları ile ilgili birçok ulusal rehber oluşturulmuş ve literatürde yerini almıştır (10, 18, 30-32). Bununla birlikte COVID-19 hastalarında kronik dönemde pulmoner rehabilitasyonun etkisini araștıran sadece bir bilimsel araştırma tamamlanmıştır. Bu araştırmada Liu ve ark, 65 yaş üzerinde 72 COVID-19 hastasını prospektif, randomize ve kontrollü olarak değerlendirmişlerdir. Hastaların 32'sine PR uygulanırken, 32'si kontrol grubunu oluşturmuştur. PR protokolü 6 hafta, haftada 2 gün, günde $10 \mathrm{dk}$ olarak belirlenmiştir. Hastalara uygulanan PR programında ise; solunum kas eğitimi (threshold PEP ile), öksürme egzersizi (10 tekrar), diyafram solunumu egzersizi, üst ekstremite göğüs kaslarına germe egzersizleri bulunmaktadır. Kontrol grubuna ise ev egzersizleri verilmiştir. PR grubunda 6 hafta sonunda hem SFT hem de DLCO ölçümlerinde istatistiksel olarak anlamlı düzelme saptanmıştır. Altı dakika yürüme testi (6DYT)'de ise PR grubunda yaklaşı $60 \mathrm{~m}$ artış elde edilmiştir. SF-36'nın tüm alt başlıklarında, anksiyete ve depresyon ölçeklerinde PR grubunda anlamlı düzelme sağlanmıştır(33). Bu araştırma COVID-19 hastalarında PR'nin etkili olduğunu gösteren ilk araștırmadır. Hastaların özellikle yüksek FEV1 ölçümüne sahip olmaları, özellikle rekstriktif paternlerinin olması DLCO düşüklüğü ile seyreden pulmoner fibrozisi göz önünde bulundurarak PR programlarını oluşturmamız gerektiğini desteklemektedir. Bu araştırmada hastaların aerobik egzersiz düzeyleri sadece 6DYT ile değerlendirilmiş, kardiyopulmoner egzersiz testi yapılmamıștır. Ayrıca hastalara herhangi bir aerobik egzersiz programı da uygulanmamıştır.

COVID-19 hastalarında hipoksemi önemli bir klinik bulgu olmaktadır. Bu hastalarda egzersiz sırasında O2 satürasyonunun takibi mutlaka yapılmalıdır. 6DYT hastaların egzersiz kapasitesinin saptanması için güvenli olarak kullanılabilecek, submaksimal bir testtir ve birçok hastalıkta kullanılmaktadır. KOAH hastalarında uygulanan PR'nın etkili olduğunu gösteren, 6DYT'de klinik anlamlı değişiklik $54 \mathrm{~m}$ olarak kabul edilmektedir(34). İAH'da ise 6DYT'nin minimal klinik anlamlı fark değeri $24-45 \mathrm{~m}$ arasındadır $(35,36)$. İAH'da egzersiz sirasinda SPO2'nin \% 85 hatta \% 90'1n üzerinde tutulması önerilmektedir. Egzersiz sırasında hastalara $\mathrm{O} 2$ desteği verilmesi hipoksiyi önlemekte böylece egzersiz toleransını artırmaktadır (37).

Genel olarak COVID-19 hastalarında PR planlamasında;

1. Semptom sorgulamasi: İstirahatte ve egzersiz sırasında dispne şiddeti, SPO2 değerlerinin ölçülmesi

2. Fiziksel performansin (6DYT) ve periferik kas gücünün değerlendirilmesi

3. Solunum kas gücünün değerlendirilmesi (Maksimal inspiratuar-MIP ve maksimal ekspiratuar-MEP basınç)

4. SFT ve DLCO ölçümü

5. Detaylı kardiyak değerlendirme (iskemi, aritmi, pulmoner HT)

6. Sigara, allerjene maruziyet gibi zararlı çevresel faktörlerden uzak kalınması

7. Eşlik eden hastalıkların değerlendirilmesi ve kontrol altında tutulması

8. Fonksiyonel değerlendirme yapılmalıdır.

COVID-19 hastalarında tedavi tamamlanıp PCR testi 2 kere negatif saptansa bile orofarengeal kavite ve gaitada virüsün bulunabileceğinin bildirilmesi nedeniyle, PR ihtiyacı olan hastaların standart ünitelerde tedaviye alınabilmesi için en 
az 1 aylık süre gerekir (38). Bu hastalarda rehabilitasyon öncesinde antikor testlerinin yapilması daha da uygun olabilir.

COVID-19 pandemisi sırasında İtalya başta olmak üzere tüm Avrupa ülkelerinde hem KPR üniteleri hasta saylarını azaltmış hatta tamamen durdurmuşlardır (39). Ülkemizde de benzer şekilde KPR üniteleri hasta almamıştır. Pandemi sonrasında bu ünitelerde normalleşme süreci ile ilgili de birçok düzenleme yapılması gerekmektedir (40, 41). Özellikle aerosol yayılımına neden olan testlerin (MIP, MEP, SFT, KPET) elektif olgular için ertelenmesi birçok rehberde önerilmektedir $(12,18,38,39)$. Bir yandan da hem COVID-19 hastalarının hem de zaten KPR endikasyonu olan hastaların biran önce rehabilitasyona alınması önem arz etmektedir. Rehberlerde COVID-19 geçiren hastaların 1 ay sonunda genel rehabilitasyon kliniklerine kabul edilebileceği görüşü kabul görmektedir $(6,12,42,43)$.

\section{SONUÇ}

COVID-19'un öncelikli olarak pulmoner ve kardiyak tutulumunun gözlenmesinin nedeniyle ve komorbiditelerin eklenmesi ile ortaya çıkan kompleks sorunda hastaya özgü KPR programlarının oluşturulması kaçınılmazdır. COVID-19 sonrası bireyler pulmoner ve kardiyak fonksiyonları, egzersiz kapasiteleri, psikososyal durumları, beslenme düzeylerindeki kayıplar açısından KPR ekibi tarafından değerlendirilmeli ve bireyselleştirilmiş KPR programına alınmalıdır.

\section{Etik Kurul Onayı}

Deneysel ve insan ürünü kullanılmadığından etik kurul başvurusu gerekmemiştir.

\section{Çıkar Çatışması}

Yazarla bu araştırma vemakale için herhangi bir çıkar çatışması olmadığını beyan ederler.

\section{Finansal Destek}

Herhangi bir finansal destek alınmamıştır.

Yazarların Makaleye Katkı Beyanı

Yazının fikir, tasarım, kaynak tarama, yazım ve yorumlar yazara aittir.

\section{Hakem Değerlendirmesi}

Yazı hakemlik süreci sonrası yayınlanmaya kabul edilmiştir.

\section{KAYNAKLAR}

1. Sahu KK, Mishra AK, Lal A. COVID-2019: Update on epidemiology, disease spread and management. Monaldi Arch Chest Dis. 2020;90(1).

2. SARS-CoV-2 C-, Bilim ER, 2020. KÇN, (https://covid19bilgi. saglik.gov.tr/d, epo/rehberler/COVID-, 19_Rehberi.pdf).
3. https://covid19.saglik.gov.tr/.

4. Rational use of personal protective equipment for coronavirus disease (COVID-19) and considerations during severe shortages. (https://apps.who.int/iris/bitstream/ handle/10665/331695/WHO-2019-nCov-IPC_PPE_use2020.3-eng.pdf)

5. Herridge MS, Cheung AM, Tansey CM, Matte-Martyn A, Diaz-Granados N, Al-Saidi F, et al. One-year outcomes in survivors of the acute respiratory distress syndrome. N Engl J Med. 2003;348(8):683-693.

6. Sheehy LM. Considerations for postacute rehabilitation for survivors of COVID-19. JMIR Public Health Surveill. 2020;6(2):e19462.

7. Zhu J, Ji P, Pang J, Zhong Z, Li H, He C, et al. Clinical characteristics of 3062 COVID-19 patients: A meta-analysis. J Med Virol. 2020;10.1002/jmv.25884.

8. Wang D, Hu B, Hu C, Zhu F, Liu X, Zhang J, et al. Clinical Characteristics of 138 Hospitalized Patients With 2019 Novel Coronavirus-Infected Pneumonia in Wuhan, China. JAMA. 2020;323(11):1061-1069.

9. Kurtaiş Aytür Y, Köseoğlu BF, Özyemişçi Taşkıran Ö, Ordu-Gökkaya NK, Ünsal Delialioğlu S, Sonel Tur B, et al. Pulmonary rehabilitation principles in SARS-COV-2 infection (COVID-19): A guideline for the acute and subacute rehabilitation. Turk J Phys Med Rehabil. 2020;66(2):104-120.

10. Yang LL, Yang T. Pulmonary rehabilitation for patients with coronavirus disease 2019 (COVID-19). Chronic Dis Transl Med. 2020;6(2):79-86.

11. Memikoğlu O, Genç V. COVID 19. 1. Baskı. Ankara Üniversitesi Basımevi, 2020. p.117.

12. Li J. Rehabilitation management of patients with COVID-19. Lessons learned from the first experiences in China. Eur J Phys Rehabil Med. 2020;56(3):335-338.

13. Jin YH, Cai L, Cheng ZS, Cheng H, Deng T, Fan YP, et al. A rapid advice guideline for the diagnosis and treatment of 2019 novel coronavirus (2019-nCoV) infected pneumonia (standard version). Mil Med Res. 2020;7(1):4.

14. Lazzeri M, Lanza A, Bellini R, Bellofiore A, Cecchetto S, Colombo A, et al. Respiratory physiotherapy in patients with COVID-19 infection in acute setting: A Position Paper of the Italian Association of Respiratory Physiotherapists (ARIR). Monaldi Arch Chest Dis. 2020;90(1).

15. Thomas P, Baldwin C, Bissett B, Boden I, Gosselink R, Granger CL, et al. Physiotherapy management for COVID-19 in the acute hospital setting: clinical practice recommendations. J Physiother. 2020;66(2):73-82.

16. Chinese Association of Rehabilitation Medicine, Respiratory Rehabilitation Committee of Chinese Association of Rehabilitation Medicine, Cardiopulmonary Rehabilitation Group of Chinese Society of Physical Medicine and Rehabilitation. Recommendations for respiratory rehabilitation of coronavirus disease 2019 in adult. Zhonghua Jie He He Hu Xi Za Zhi 2020;43(4):308-314 
17. Zhao HM, Xie YX, Wang C. Recommendations for respiratory rehabilitation in adults with coronavirus disease 2019. Chin Med J (Engl). 2020;133(13):1595-1602.

18. Kurtaiş Aytür Y, Köseoğlu F, Özyemişçi Taşkıran Ö, Ordu Gökkaya NK, Ünsal Delialioğlu S, et al. SARS-CoV-2 (COVID-19) sonrası pulmoner rehabilitasyon prensipleri: Akut ve subakut sürecin yönetimi için rehber. J PMR Sci. 2020;23(2):111-128.

19. Dammeyer J, Dickinson S, Packard D, Baldwin N, Ricklemann C. Building a protocol to guide mobility in the ICU. Crit Care Nurs Q. 2013;36(1):37-49.

20. Hiner C, Kasuya T, Cottingham C, Whitney J. Clinicians' perception of head-of-bed elevation. Am J Crit Care. 2010;19(2):164-167.

21. Bhatia RT, Marwaha S, Malhotra A, Iqbal Z, Hughes C, Borjesson $\mathrm{M}$, et al. Exercise in the severe acute respiratory syndrome Coronavirus-2 (SARS-CoV-2) era: A question and answer session with the experts endorsed by the section of Sports Cardiology \& Exercise of the European Association of Preventive Cardiology (EAPC). Eur J Prev Cardiol. 2020;27(12):1242-1251.

22. Fan E, Zanni JM, Dennison CR, Lepre SJ, Needham DM. Critical illness neuromyopathy and muscle weakness in patients in the intensive care unit. AACN Adv Crit Care 2009;20(3):243-253.

23. COVID-19 Servis Hastaları için Egzersiz Föyü. (https://www. tftr.org.tr/covid19/files/doc04.pdf.)

24. Alger SE, Brager AJ, Balkin TJ, Capaldi VF, Simonelli G. Effect of cognitive load and emotional valence of distractors on performance during sleep extension and subsequent sleep deprivation. Sleep. 2020;43(8):zsaa013.

25. Klok FA, Boon G, Barco S, Endres M, Geelhoed JJM, Knauss S, et al. The Post-COVID-19 functional status (PCFS) scale: A tool to measure functional status over time after COVID-19. Eur Respir J. 2020;2001494.

26. Li J. Rehabilitation management of patients with COVID-19. Lessons learned from the first experiences in China. Eur J Phys Rehabil Med. 2020;56(3):335-338.

27. Herridge MS, Tansey CM, Matte A, Tomlinson G, DiazGranados N, Cooper A, et al. Functional disability 5 years after acute respiratory distress syndrome. N Engl J Med. 2011;364(14):1293-1304.

28. Herridge MS. Recovery and long-term outcome in acute respiratory distress syndrome. Crit Care Clin. 2011;27(3):685704.

29. Elizabeth Wilcox M, Herridge MS. Clinical year in review III: mechanical ventilation, acute respiratory distress syndrome, nonpulmonary intensive care unit, and quality performance assessment metrics in your practice. Proc Am Thorac Soc. 2011;8(5):404-410.

30. Zhu C, Wu Y, Liu H, Ban Y, Ma X, Zhang Z. Early pulmonary rehabilitation for SARS-CoV-2 pneumonia: Experience from an intensive care unit outside of the Hubei province in China. Heart Lung. 2020;S0147-9563(20)30141-2.
31. Simonelli C, Paneroni M, Fokom AG, Saleri M, Speltoni I, Favero I, et al. How the COVID-19 infection tsunami revolutionized the work of respiratory physiotherapists: An experience from Northern Italy. Monaldi Arch Chest Dis. 2020;90(2).

32. Bryant MS, Fedson SE, Sharafkhaneh A. Using telehealth cardiopulmonary rehabilitation during the COVID-19 pandemic. J Med Syst 2020;44(7):125.

33. Liu K, Zhang W, Yang Y, Zhang J, Li Y, Chen Y. Respiratory rehabilitation in elderly patients with COVID-19: A randomized controlled study. Complement Ther Clin Pract. 2020;39:101166.

34. Holland A, Hill C. Physical training for interstitial lung disease. Cochrane Database Syst Rev. 2008(4):CD006322.

35. du Bois RM, Weycker D, Albera C, Bradford WZ, Costabel U, Kartashov A, et al. Six-minute-walk test in idiopathic pulmonary fibrosis: Test validation and minimal clinically important difference. Am J Respir Crit Care Med. 2011;183(9):1231-1237.

36. ATS Committee on Proficiency Standards for Clinical Pulmonary Function Laboratories. ATS statement: Guidelines for the six-minute walk test. Am J Respir Crit Care Med. 2002;166(1):111-117.

37. Wytrychowski K, Hans-Wytrychowska A, Piesiak P, Majewska-Pulsakowska M, Rozek-Piechura K. Pulmonary rehabilitation in interstitial lung diseases: A review of the literature. Adv Clin Exp Med. 2020;29(2):257-264.

38. Severin R, Arena R, Lavie CJ, Bond S, Phillips SA. Respiratory muscle performance screening for infectious disease management following COVID-19: A highly pressurized situation. Am J Med. 2020;S0002-9343(20)30347-8.

39. Vigorito C, Faggiano P, Mureddu GF. COVID-19 pandemic: what consequences for cardiac rehabilitation? Monaldi Arch Chest Dis. 2020;90(1).

40. Babu AS, Arena R, Ozemek C, Lavie CJ. COVID-19: A time for alternate models in cardiac rehabilitation to take centre stage. Can J Cardiol. 2020;36(6):792-794.

41. Thomas E, Gallagher R, Grace SL. Future-proofing cardiac rehabilitation: Transitioning services to telehealth during COVID-19. Eur J Prev Cardiol. 2020;2047487320922926.

42. Iannaccone S, Alemanno F, Houdayer E, Brugliera L, Castellazzi P, Cianflone D, et al. COVID-19 rehabilitation units are twice as expensive as regular rehabilitation units. J Rehabil Med. 2020;52(6):jrm00073.

43. Sole G, Salort-Campana E, Pereon Y, Stojkovic T, Wahbi K, Cintas P, et al. Guidance for the care of neuromuscular patients during the COVID-19 pandemic outbreak from the French Rare Health Care for Neuromuscular Diseases Network. Rev Neurol (Paris). 2020;176(6):507-515. 